\title{
Antimicrobial Activity of Essential Oils of Cinnamomum zeylanicum, Mentha piperita, Zataria multiflora Boiss and Thymus vulgaris Against Pathogenic Bacteria
}

Ali Mohammadi (PhD)

Department of Biology, Faculty of Sciences, Alzahra University, Tehran, Iran

Maryam Hashemi $(\mathbf{P h D})$

Department of Microbial

Biotechnology and Biosafety,

Agricultural Biotechnology Research

Institute of Iran (ABRII), Karaj, Iran

Masoud Hosseini (PhD)

Department of Microbiology, Faculty

of Biological Sciences, Shahid

Beheshti University, Tehran, Iran

Email: Al_Mohammadi@Sbu.ac.ir

Corresponding Author: Ali

Mohammadi

Tel: +982129902721

Address: Faculty of Sciences, Alzahra University, Tehran, Iran

Received : 14 Dec 2014

Revised: 06 Jan 2015

Accepted: 24 Jan 2015

\section{ABSTRACT}

Background and Objective: Considering the increasing tendency of public towards green consumption and the dangers of artificial additives, this study aimed to assess antibacterial activity of essential oils of Cinnamomum zeylanicum, Mentha piperita $L$., Zataria multiflora Boiss and Thymus vulgaris against three important pathogenic and spoilage bacteria (Pseudomonas fluorescens, Erwinia carotovora and Escherichia coli).

Methods: After obtaining the essential oils from Magnolia Co., their antimicrobial activity was assessed using broth microdilution method by determining the minimum inhibitory concentration (NIC50, MIC90) and minimum bactericidal concentration (NBC). All experiments were performed in triplicate and the data were analyzed using the GraphPad software and Duncan's new multiple range test.

Results: All essential oils showed antimicrobial activity in a concentration-dependent manner. Increasing the concentration of essential oils from $0.01 \%$ to $4 \%$ (v/v) significantly enhancing the antibacterial activity. The statistical calculations and comparison of data showed that the essential oils of $C$. zeylanicum and Z. multiflora performed better compared to the other two essential oils, due to having lower values of MIC50 $(\leq 0.1 \%)$, MIC90 $(\leq 0.4 \%)$ and $\operatorname{MBC}(\leq 1 \%)(\mathrm{P}<0.05)$.

Conclusion: Considering the high antimicrobial activity of essential oils of $C$. zeylanicum and Z. multiflora, they can be used as effective food additives with fewer side effects. However, further studies are being conducted on the effectiveness of essential oils on the growth of other microorganisms and their results will be published soon.

Keywords: Essential 0ils, Antimicrobial, Pathogenic Bacteria, Cinnamomum Zeylanicum, Zataria Multiflora Boiss. 


\section{INTRODUCTION}

Considering the increasing tendency of public towards green consumption and the risks of artificial additives, the plant sources such as spices, herbs, essential oils and other compounds with antibacterial properties are among the best options that can increase the shelf life of foodstuff $(1,2)$.

Essential oils are the volatile liquids that have antimicrobial properties. Many studied have reported the antibacterial, antifungal and insecticidal effects of essential oils and plant extracts $(3,4)$. Given that essential oils have long been traditionally used to make pleasant taste in food, the simultaneous presence of the antimicrobial properties can encourage their use for this purpose (5). The U.S. Food and Drug Administration have also certified essential oils as generally recognized as safe (GRAS) (6). The antimicrobial effect of essential oils of four plants were evaluated and compared in this study.

Cinnamon (Cinnamomum zeylanicum) is an aromatic herb from the family Lauraceae that has been widely used for thousands of years as a food flavoring and seasoning ingredient (7). Essential oil of $C$. zeylanicum is one of the most important medicinal parts of this herb which is rich in compounds such eugenol and cinnamaldehyde $(1,8)$. The antifungal (9), antibacterial (10, 11), antioxidant and antimutagenic (12) activities of these compounds in this essential oil have been reported. Peppermint (Mentha piperita L., Labiatae family) has long been known to have several pharmaceutical, food and health applications. The essential oil of peppermint is among the most important medicinal parts of this plant that can be extracted from different parts of the plant such as aerial organs and leaves (13). Menthol is a main constituent of this essential oil and is reported to have antibacterial $(14,15)$ and antifungal $(16,17)$ properties.

Thymus vulgaris (family Lamiaceae) has long been traditionally used for its special features as a sputum inducer, antitussive, anticonvulsant, vermicide, carminative and diuretic agent. The antibacterial and antifungal properties of $T$. vulgaris essential oil constituents including thymol and carvacrol have been reported $(18,19)$.
Zataria multiflora Boiss (family Lamiaceae) grows wild in southern and central regions of Iran, Pakistan and Afghanistan. Some studies reported the phenolic compound of carvacrol as the main constituent of this essential oil, while other studies reported thymol (carvacrol's isomer) (20). The antiseptic, anesthetic, antioxidant, antifungal and antibacterial properties of these compounds are well-demonstrated $(21,22)$. This study aimed to compare the antibacterial effect of the mentioned essential oils on different stages of growth of the following three important pathogenic and spoilage bacteria:

1. Pseudomonas fluorescens, as the cause of spoilage in meat products (13) and head rot in agricultural products (23).

2. Erwinia carotovora, as the cause of various diseases in crops $(24,25)$.

3. Escherichia coli, as one of the most dangerous pathogens of the gastrointestinal tract and cause of spoilage in meat products (26).

In addition, the appropriate essential oils with specific concentrations were determined to deal with the above bacteria.

\section{MATERIAL AND METHODS}

The essential oils used in this study $(C$. zeylanicum, M. piperita, $T$. vulgaris and $Z$. multiflora) were purchased from Magnolia Co. the qualitative parameters of each essential oil such as color, odor, appearance, purity, solubility and chemical properties ( $\mathrm{pH}$, acidity, brix, etc.) were described in the specifications form along with their analysis.

The studied microbial strains including E. coli (O157: H7 ATCC 25922), P. fluorescens (ATCC 17482) and E. carotovora (PTCC No: 1675) were obtained in the form of lyophilized ampoules from the Iranian Industrial and Scientific Research Center. To activate the microbial strains, the ampules were opened under sterile conditions and primary culture was done followed by secondary culture. The cultured bacteria were stored for the next experiments and in order to maintain the viability of the bacteria, reculturing was performed every 14 days.

The spectrophotometric method of broth microdilution was used, according to the 
Clinical and Laboratory Standards Institute (CLSI) standards, to investigate the effects of essential oils on the growth of bacteria and to plot growth curves (27). The Mueller Hinton Broth (MHB) was autoclaved for about 15 minutes at $120{ }^{\circ} \mathrm{C}$ and all stages of the experiments were performed under Class II biological safety cabinet. In this study, 96-well plates $(8 \times 12)$ were used to investigate the antimicrobial activity of the essential oils. The final concentration of essential oils in the well was $0.01 \%$ to $4 \%(\mathrm{v} / \mathrm{v})$, so that $200 \mu \mathrm{l}$ of each essential oil solution with the highest concentration was added to the first column along with Tween 80 (Merck) and distilled water. Then, $100 \mu \mathrm{l}$ of cation-adjusted MHB was added to the remaining columns. Next, the serial dilutions were made from the essential oils by transferring $100 \mu \mathrm{l}$ of the solution from the first column to the next column and this was continued until the last column. At the end, the volume in each well reached $200 \mu \mathrm{l}$ by inoculating $100 \mu$ l of each bacterial inoculum into each well of the microplate. The inoculum was prepared by 16 -hour culture of the bacteria and matching its absorbance with the standard solution (equivalent to 0.5 McFarland standards) at $600 \mathrm{~nm}$, and preparing serial dilutions in the MHB to achieve a dilution of $1.25 \times 10^{6} \mathrm{CFU} / \mathrm{ml}$. Finally, final concentration of $10^{5} \mathrm{CFU} /$ well was achieved by adding the suspension to the wells. Three controls were designed for each sample. Positive controls contained bacterial suspension and lacked essential oils, while negative controls contained essential oils and lacked microbial suspension. After inoculation, the plates' caps were completely covered with Parafilm and the contents were mixed by shaking. The plates were incubated for 24 hours at $28{ }^{\circ} \mathrm{C}$ (Pseudomonas and Erwinia) and $37{ }^{\circ} \mathrm{C}$ (Escherichia). The light absorbance of each well at $600 \mathrm{~nm}$ was recorded by a spectrophotometer after the incubation and shaking. Finally, the antibacterial activity of essential oils was calculated according to the following formula (28):

Antibacterial activity $(\%)=\frac{O D c-O D s}{O D S} \times 100$

In this formula, $\mathrm{OD}_{\mathrm{s}}$ and $\mathrm{OD}_{\mathrm{c}}$ represent the optical density of the samples and the controls, respectively. The minimum inhibitory was determined by observing lack of increased optical density (OD) after 24 hours and based on the lowest concentration that would prevent the growth of strains (lack of growth in the wells). The minimum bactericidal concentration (MBC) values of the extracts was determined by subculturing $10 \mu \mathrm{l}$ of the contents of each well into the plate containing Mueller Hinton agar medium, incubation at $37{ }^{\circ} \mathrm{C}$ for 48 hours and counting colonies. The MBC is the lowest concentration of treated samples that causes the death of $99.9 \%$ of the inoculated suspension. The GraphPad software was used to calculate the MIC50 values (concentration that causes 50\% growth inhibition) of the essential oils and to plot absorbance at different concentrations. Microsoft Excel was used for plotting curves and calculation of standard deviation (SD) and error bars for each point of the curve. All experiments were performed in triplicate for each sample and the obtained results were recorded by repeating the entire experiment. Analysis of variance (ANOVA) was used in order to evaluate significant differences between the effects of various concentrations of essential oils. The Duncan's multiple range tests was applied to compare the means, if there was a significant difference. P-value $<0.05$ was considered as the statistical significance level. The statistical analysis was performed using GraphPad software (version $6)$.

\section{RESULTS}

The antimicrobial activity of the tested essential oils against each bacterium is presented in Figures 1-3. The results showed no significant difference between repetitions of a certain concentration, which indicates the accuracy of sampling.

In assessment of the antimicrobial activity of essential oils against Pseudomonas (Figure 1), the bacterial density was reduced to less than $50 \%$ in the presence of $\leq 0.08 \%$ dilution of $C$. zeylanicum, M. piperita and Z. multiflora in comparison with the controls. Moreover, $1 \%$ concentration of the mentioned essential oils completely inhibited the growth of Pseudomonas bacteria $\quad(\mathrm{P}<0.05)$. Concentrations of $\geq 0.2 \%$ T. vulgaris showed more than $50 \%$ antimicrobial effect. 
Figure 1- Percentage of inhibition for different concentrations and various types of essential oils against Pseudomonas. AB: T. vulgaris, AS: Z. multiflora, NF: M. piperita and DA: C. zeylanicum.

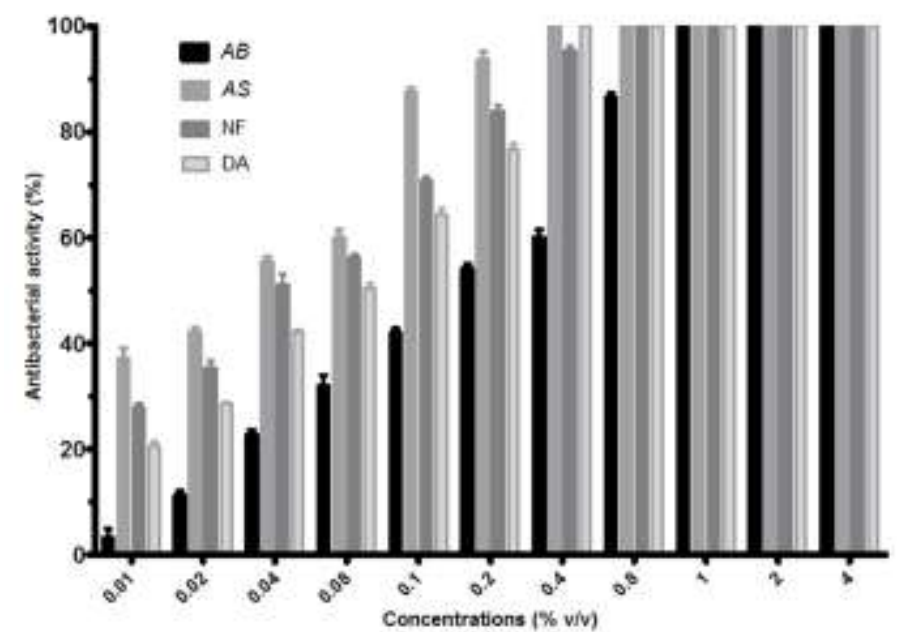

Table 1-Analysis of variance and effect of concentration and type of essential oils on growth of Pseudomonas

\begin{tabular}{|c|c|c|c|c|c|c|}
\hline Result & $\begin{array}{c}\text { probability level of } \\
\text { higher than } F\end{array}$ & F-value & $\begin{array}{c}\text { mean } \\
\text { squares }\end{array}$ & $\begin{array}{l}\text { degrees of } \\
\text { freedom }\end{array}$ & $\begin{array}{l}\text { sum of } \\
\text { squares }\end{array}$ & Source \\
\hline$* * * *$ & $P<0.0001$ & 203.82 & 214.9 & 30 & 6447 & $\begin{array}{l}\text { Essential oil } \times \text { Concentration } \\
\left(\mathbf{X}_{1} \times \mathbf{X}_{2}\right)\end{array}$ \\
\hline$* * * *$ & $P<0.0001$ & 2693 & 2841 & 3 & 8522 & Essential oil $\left(\mathbf{X}_{1}\right)$ \\
\hline \multirow[t]{2}{*}{$* * * *$} & $P<0.0001$ & 9698 & 10228 & 10 & 102282 & Concentration $\left(\mathbf{X}_{2}\right)$ \\
\hline & & & 1.055 & 88 & 92.81 & Error \\
\hline
\end{tabular}

Figure 2- Percentage of inhibition for different concentrations of essential oils against Erwinia. AB: $T$. vulgaris, AS: $Z$. multiflora, NF: $M$. piperita and DA: $C$. zevlanicum

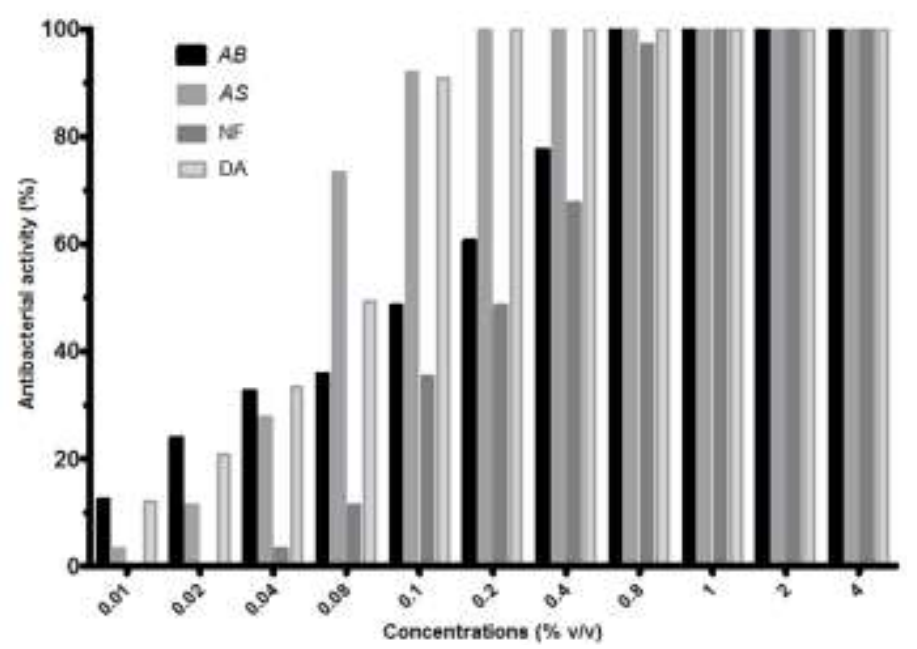

Table 2- Analysis of variance and effect of concentration and type of essential oils on growth of Erwinia

\begin{tabular}{|c|c|c|c|c|c|c|}
\hline Result & $\begin{array}{c}\text { probability level of } \\
\text { higher than } F\end{array}$ & F-value & $\begin{array}{c}\text { mean } \\
\text { squares }\end{array}$ & $\begin{array}{l}\text { degrees of } \\
\text { freedom }\end{array}$ & $\begin{array}{c}\text { sum of } \\
\text { squares }\end{array}$ & Source \\
\hline$* * * * *$ & $P<0.0001$ & 576.7 & 518.2 & 30 & 15545 & $\begin{array}{l}\text { Essential oil } \times \text { Concentration } \\
\left(\mathbf{X}_{1} \times \mathbf{X}_{2}\right)\end{array}$ \\
\hline$* * * *$ & $P<0.0001$ & 4110 & 3692 & 3 & 11077 & Essential oil $\left(\mathbf{X}_{1}\right)$ \\
\hline$* * * *$ & $P<0.0001$ & 18061 & $\begin{array}{l}16228 \\
0.8985\end{array}$ & $\begin{array}{l}10 \\
88\end{array}$ & $\begin{array}{l}162275 \\
79.07\end{array}$ & Concentration $\left(\mathbf{X}_{2}\right)$ \\
\hline
\end{tabular}

It is significant at a level of $P$-value $<0.05$. Symbol meaning; ns $P>0.05 ; * P \leq 0.05, * * P \leq 0.01,{ }^{* * *} \mathrm{P} \leq 0.001, * * * * \quad P \leq 0.0001$. 
The antimicrobial activity of the essential oils against Erwinia can be divided into three different categories (Figure 2). The first category is activity of less than $50 \%$ that was observed in concentrations of $\leq 0.1 \% \quad T$. vulgaris and $M$. piperita as well as concentrations of $<0.08 \%$ C. zeylanicum and Z. multiflora $(\mathrm{P}<0.05)$. The second category contains concentrations of $\geq 0.08 \%$ of $C$. zeylanicum and $Z$. multiflora, as well as $\geq$ $0.02 \%$ concentration of $T$. vulgaris and $\geq 0.4 \%$ concentration of $M$. piperita, which had antibacterial activity of $50-90 \%$. The third category with complete antimicrobial activity (100\%) can be observed at concentrations of $\geq$ $1 \%$ of all essential oils. Moreover, the concentration of $\leq 0.2 \% C$. zeylanicum and $Z$. multiflora could completely inhibit the growth of Erwinia (100\%). As demonstrated in the E. coli growth curve (Figure 3), the essential oils of $T$. vulgaris and $M$. piperita were less effective at low concentrations. The concentration of $\geq 0.04 \% T$. vulgaris and $\geq$ $0.2 \%$ M. piperita caused more than $50 \%$ inhibition in the growth of E.coli $(\mathrm{P}<0.05)$. This effect was observed at concentration of $\geq$ $0.1 \%$ C. zeylanicum and $Z$. multiflora. The growth of this bacterium was completely inhibited at concentration of $\geq 0.8$ for all essential oils. The analysis of variance showed the significant effect of both factors of essential oil type and concentration at $99 \%$ confidence level (Table 1-3).

The most effective essential oil with highest antimicrobial activity

In order to identify the most effective essential oil, the values of MIC50, MIC90 and MBC were determined for each essential oil (Table $4)$. The results of this table and the statistical calculations showed that the essential oils of C. zeylanicum and Z. multiflora have better efficiency against all bacterial samples compared to the other two essential oils ( $p$ $<0.05)$. In addition, the comparison of MIC50, MIC90 and MBC values indicated that these values are the lowest in essential oils of $C$. zeylanicum and $Z$. multiflora. Lower value of MIC50 for an antimicrobial substance certainly indicates higher antimicrobial properties for inhibition of bacterial growth at lower amounts. In conclusion, the essential oils of $C$. zeylanicum and Z. multiflora showed better performance.

Figure 3- Percentage of inhibition for different concentrations of essential oils against E.coli. AB: T. vulgaris, AS: $Z$. multiflora, NF: M. piperita and DA: $C$. zeylanicum.

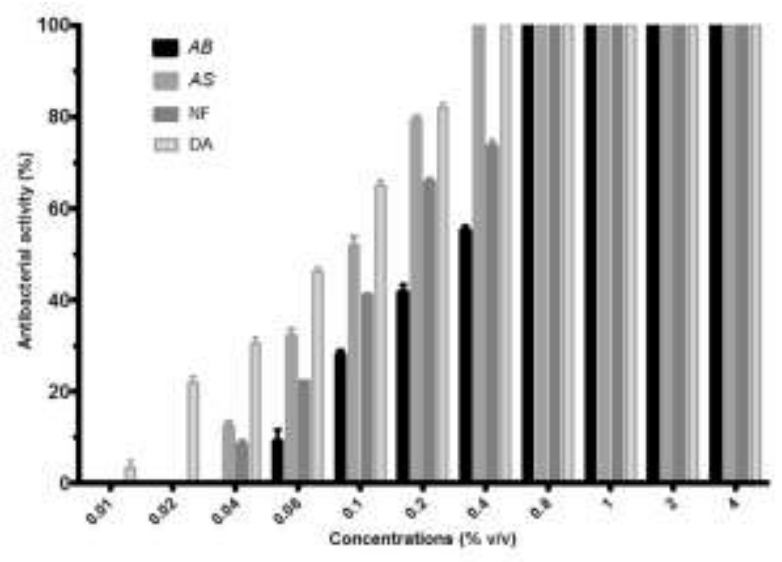

Table 3- Analysis of variance and effect of concentration and type of essential oils on growth of E.coli

\begin{tabular}{|c|c|c|c|c|c|c|}
\hline Result & $\begin{array}{c}\text { probability level of } \\
\text { higher than } F\end{array}$ & F-value & $\begin{array}{l}\text { mean } \\
\text { squares }\end{array}$ & $\begin{array}{c}\text { degrees of } \\
\text { freedom }\end{array}$ & $\begin{array}{c}\text { sum of } \\
\text { squares }\end{array}$ & Source \\
\hline$* * * *$ & $P<0.0001$ & 340.3 & 258 & 30 & 7740 & $\begin{array}{l}\text { Essential oil } \times \text { Concentration } \\
\left(\mathbf{X}_{1} \times \mathbf{X}_{2}\right)\end{array}$ \\
\hline$* * * * *$ & $P<0.0001$ & 2351 & 1782 & 3 & 5347 & Essential oil $\left(\mathbf{X}_{1}\right)$ \\
\hline$* * * *$ & $P<0.0001$ & 26345 & $\begin{array}{l}19974 \\
0.7582\end{array}$ & $\begin{array}{l}10 \\
88\end{array}$ & $\begin{array}{c}199741 \\
66.72\end{array}$ & $\begin{array}{l}\text { Concentration }\left(\mathbf{X}_{2}\right) \\
\text { Error }\end{array}$ \\
\hline
\end{tabular}

It is significant at a level of $P$-value $<0.05$. Symbol meaning; ns $P>0.05 ; * P \leq 0.05, * * P \leq 0.01, * * * P \leq 0.001, * * * * \quad P \leq 0.0001$. 
Table 4- Values of MIC90, MIC50 and MBC for the essential oils against the strains tested

\begin{tabular}{|c|c|c|c|c|c|c|c|c|c|}
\hline \multicolumn{3}{|c|}{$\begin{array}{c}P . \text { fluorescens } \\
\%(\mathrm{v} / \mathrm{v})\end{array}$} & \multicolumn{3}{|c|}{$\begin{array}{c}\text { E. carotovora } \\
\%(\mathrm{v} / \mathrm{v})\end{array}$} & \multicolumn{3}{|c|}{$\begin{array}{l}\text { E. coli } \\
\%(\mathrm{v} / \mathrm{v})\end{array}$} & \multirow[t]{2}{*}{ Essential oil } \\
\hline MBC & MIC $_{90}$ & $\mathrm{MIC}_{50}$ & MBC & $\mathrm{MIC}_{90}$ & $\mathrm{MIC}_{50}$ & MBC & $\mathrm{MIC}_{90}$ & $\mathrm{MIC}_{50}$ & \\
\hline $4 \%$ & $1 \%$ & $0.27 \%$ & $2 \%$ & $0.8 \%$ & $0.16 \%$ & $4 \%$ & $0.8 \%$ & $0.33 \%$ & T. vulgaris \\
\hline $1 \%$ & $0.4 \%$ & $0.04 \%$ & $0.8 \%$ & $0.2 \%$ & $0.06 \%$ & $1 \%$ & $0.4 \%$ & $0.1 \%$ & Z. multiflora \\
\hline $1 \%$ & $0.4 \%$ & $0.06 \%$ & $0.8 \%$ & $0.2 \%$ & $0.06 \%$ & $1 \%$ & $0.4 \%$ & $0.1 \%$ & C. zeylanicum \\
\hline $4 \%$ & $0.8 \%$ & $0.08 \%$ & $2 \%$ & $1 \%$ & $0.26 \%$ & $2 \%$ & $0.8 \%$ & $0.16 \%$ & M. piperita \\
\hline
\end{tabular}

\section{DISCUSSION}

The antibacterial effects of essential oils and plant extracts for controlling the growth of food-borne pathogens and spoilage microorganisms have been reported in several studies $(3,4,29)$. According to previous studies, the antimicrobial activity of these compounds is exerted through damaging the structure and function of bacterial cell membrane. These studies also show that the composition, structure and functional groups play an important role in determination of the antimicrobial activity (30).

Based on the results of the present study, the essential oils of $C$. zeylanicum and $Z$. multiflora exhibited the highest antimicrobial activity. The antimicrobial properties of these two essential oils against many spoilage bacteria and fungi have been reported $(9,31)$. For example, Amini et al. (2012) and Abdolmaleki et al. (2010) have reported the antimicrobial properties of $Z$. multiflora against some plant pathogenic microorganisms $(31,32)$. Furthermore, several studied have demonstrated the antimicrobial activity of $C$. zeylanicum essential oil against various microorganisms. This essential oil is highly effective against Gram-positive and Gramnegative bacteria (33). Matan et al. demonstrated that the essential oil of $C$. zeylanicum is capable of inhibiting the growth of main spoilage microorganisms in food with average moisture (34). In this study similar to the other studies, the antimicrobial activity of this essential oil has been evident against microorganism tested. This substance was able to inhibit the growth of E. coli, P. fluorescens and $E$. carotovora to a great extent. The results of the previous studies showed that the antimicrobial activity of the plant extracts is associated with the content of secondary metabolites (e.g. alkaloids, phenolics, flavonoids and terpenoids) (35).
The Phenolic compounds (such as carvacrol), which are found in the hydrophobic part of the essential oil, may be dissolved in the hydrophobic cytoplasmic membrane and cause collapse and loss of adenosine triphosphate that will eventually lead to cell death (36). The antimicrobial activity of $C$. zeylanicum is related to its large quantities of eugenol (1) and cinnamaldehyde (8), while cinnamaldehyde has been regarded as the main compound of this essential oil, responsible for its antibacterial activity (37, 38). Cinnamaldehyde exerts its antimicrobial activity by binding to bacterial proteins through its carbonyl group and inhibiting the carboxylation of amino acids (1). In other studies, it is suggested that cinnamaldehyde and eugenol prevent the production of a necessary enzyme by the bacteria that may inhibit the growth of bacteria by damaging the bacterial cell wall (39).

According to the results of various studies, the antimicrobial activity of $Z$. multiflora is mainly because it contains high percentages of thymol and carvacrol, which are considered as antibacterial agents $(40,41)$. In this regard, Ponce et al. (2008) reported that carvacrol can easily inhibit the growth of Listeria monocytogenes (42). In another study, the inhibitory effect of carvacrol on pathogenic bacteria including E. coli $(\mathrm{O} 157: \mathrm{H} 7)$ and Salmonella enterica has been reported (43).

However, considering the large number of different chemical compounds in this essential oil, the antimicrobial activity cannot be easily attributed to a specific component (44). Pcymene is among other biologically effective compounds in thyme that facilitates carvacrol's transfer through the cytoplasmic membrane of bacteria and increases the antibacterial activity. This has been well demonstrated by Ultee et al. in foodborne 
pathogens (Bacillus cereus) (45). According to studies of Talebzadeh et al. and Jirovetz et al., the other constituents of $Z$. multiflora essential oil such as $\gamma$-terpinene, $\alpha$-terpinene and Myrcene are also capable of inhibiting the growth of some bacteria $(44,46)$. These compounds can be different depending on age, phases of growth (vegetative growth, early flowering, full flowering and fruit maturation), climate, soil composition and organ of the plant $(47,48)$. Accordingly, the antimicrobial activity of this essential oil should be assessed considering these variables. Similar to the present study, El-Zemity et al. and Al-Ani et al. investigated the effectiveness of $C$. zeylanicum essential oil on E. carotovora (49, 50). However, the mentioned studies used the pour plate method, and the values of MIC, MBC and MIC50 were not reported. Calculating the amount of MIC, MBC and MIC50 can determine the scope of antimicrobial activity as well as the exact amount of antimicrobial substances required to eliminate pathogenic bacteria. The results of the present study using the broth microdilution method, showed higher antimicrobial effect of the essential oil compared to the mentioned studies. In our study, the antimicrobial activity of $C$. zeylanicum essential oil at concentrations of $0.1 \%$ and $0.2 \%$ were $90 \%$ and $100 \%$, respectively. While, the other studies indicated that these compounds were capable of inhibiting the bacterial growth only at high concentrations $(0.5 \%)$. The possible important reasons for the results' inconsistencies include organ type, height and geographical location of the plant used as well as the tested microorganisms. Furthermore, the other internal and external factors that affect the antimicrobial performance of essential oil such as temperature, $\mathrm{pH}$ and methods used should not be neglected (51). About the present study, the method used (broth microdilution) to assess the antimicrobial properties may partly explain the differences in the results. It seems that the antimicrobial performance of essential oils can be better revealed by implementing the microdilution method in which the essential oil is in contact with the liquid medium. Moreover, the temperature of the medium in the pour plate method (used in the mentioned studies) can significantly reduce the antimicrobial properties. Therefore, it is suggested using and comparing different methods for assessing the antimicrobial activity of essential oils.

\section{CONCLUSION}

The results indicate the antibacterial effect of the essential oils, particularly $C$. zeylanicum and $Z$. multiflora against some pathogenic bacteria. These essential oils can be used as natural antibiotics with fewer side effects than chemical antibiotics to deal with bacterial pathogens.

\section{ACKNOWLEDGMENTS}

We would like to show our gratitude to the former and current heads of Agricultural Biotechnology Research Institute of Iran, Dr. Khayyam Nekouee and Dr. Ghareyazi for their assistance in this research.

\section{CONFLICT OF INTEREST}

All contributing authors declare no conflicts of interest. 


\section{REFERENCES}

1. Burt S. Essential oils: their antibacterial properties and potential applications in foods - a review. Int $\mathrm{J}$ Food Microbiol. 2004; 94(3): 223-53. PMID:15246235.

2. Moosavy M-H, Basti AA, Misaghi A, Salehi TZ, Abbasifar R, Mousavi $\mathrm{HAE}$, et al. Effect of Zataria multiflora Boiss . essential oil and nisin on Salmonella typhimurium and Staphylococcus aureus in a food model system and on the bacterial cell membranes. Food Res Int. 2008; 41(10): 1050-7.

3. Alma M, Ertas M, Nitz S, Kollmannsberger $\mathrm{H}$. Chemical composition and content of essential oil from the bud of cultivated Turkish clove. BioResources. 2007; 2(2): 265-9.

4. Muyima N, Nziweni S, Mabinya L. Antimicrobial and antioxidant activities of Tagetes mimuta Lippia javanica and Foeniculum vulgar essential oils from eastern cape province of south Africa. JEOBP; 2004; 7(1): 68-78.

5. Ghahreman A. Flora of Iran. Tehran: Research Institute of Forests and Rangelands 250p-col illus Fr, En, Pe Icones. Maps Geog. 1997; 2: 102-5.

6. Smid EJ, Gorris LG. Natural antimicrobials for food preservation. Agrotechnological research institute, Wageningene, the Netherland. 1999: 285-308.

7. Mallavarapu GR, Ramesh S, Chandrasekhara R, Rajeswara Rao B, Kaul P, Bhattacharya A. Investigation of the essential oil of cinnamon leaf grown at Bangalore and Hyderabad. Flavour Fragrance J. 1995; 10(4): 23942.

8. Bassolé IHN, Juliani HR. Essential oils in combination and their antimicrobial properties. Molecules. 2012; 17(4): 3989-4006.

9. Mohammadi A, Hashemi M, Hosseini S. The control of Botrytis fruit rot in strawberry using combined treatments of Chitosan with Zataria multiflora or Cinnamomum zeylanicum essential oil. J Food Sci Tech. 2015;52(11):7441-8

10. Oussalah M, Caillet S, Saucier L, Lacroix M. Inhibitory effects of selected plant essential oils on the growth of four pathogenic bacteria: E. coli O157: H7,Salmonella Typhimurium, Staphylococcus aureus and Listeria monocytogenes. Food control. 2007; 18(5): 41420.

11. Mohammadi, A., Hashemi, M., \& Hosseini, S. M. Postharvest treatment of nanochitosan-based coating loaded with Zataria multiflora essential oil improves antioxidant activity and extends shelf-life of cucumber. $\mathrm{J}$ Food Sci. 2016; 33: 580-8.

12. Jayaprakasha G, Negi P, Jena B, Jagan Mohan Rao L. Antioxidant and antimutagenic activities of Cinnamomum zeylanicum fruit extracts. J Food Compost Anal. 2007; 20(3): 330-6.

13. Lebert I, Begot C, Lebert A. Growth of Pseudomonas fluorescens and Pseudomonas fragi in a meat medium as affected by $\mathrm{pH}(5.8-7.0)$, water activity $(0.97-1.00)$ and temperature $\left(7-25^{\circ} \mathrm{C}\right)$. Int $\mathrm{J}$ Food Microbiol. 1998; 39(1-2): 53-60.

14. Tassou C, Drosinos E, Nychas G. Effects of essential oil from mint (Mentha piperita) on Salmonella enteritidis and Listeria monocytogenes in model food systems at 4 and 10 C. J Appl Microbiol. 1995; 78(6): 593-600.
15. Andoğan $\mathrm{BC}$, Baydar H, Kaya S, Demirci $\mathrm{M}$, Özbaşar D, Mumcu E. Antimicrobial activity and chemical composition of some essential oils. Arch Pharmacal Res. 2002; 25(6): 860-4.

16. Bouchra C, Achouri M, Idrissi Hassani L, Hmamouchi M. Chemical composition and antifungal activity of essential oils of seven Moroccan Labiatae against $\langle$ i Botrytis cinerea $\langle/ i\rangle$ Pers: Fr. J Ethnopharmacol. 2003; 89(1): 165-9.

17. Chaumont J, Senet J. Antagonistic properties of higher plants against fungal parasites of man from food contaminants: screening of 200 fungi. Plant Med Phytother. 1978; 12: 186-96.

18. Al-Bayati FA. Synergistic antibacterial activity between Thymus vulgaris and Pimpinella anisum essential oils and methanol extracts. J Ethnopharmacol. 2008; 116(3): 403-6. doi: 10.1016/j.jep.2007.12.003.

19. Rota MC, Herrera A, Martínez RM, Sotomayor JA, Jordán MJ. Antimicrobial activity and chemical composition of Thymus vulgaris,Thymus zygis and Thymus hyemalis essential oils. Food Control. 2008; 19(7): 681-7. doi:10.1016/j.foodcont.2007.07.007.

20. Sajed H, Sahebkar A, Iranshahi M. Zataria multiflora Boiss .(Shirazi thyme)-An ancient condiment with modern pharmaceutical uses. J Ethnopharmacol. 2013; 145(3): 686-98.

21. Lahooji A, Mirabolfathy M, karami-osboo R. Effect of Zataria multiflora AND Satureja hortensis essential oils, thymol and carvacrol on growth of Fusarium gramineum isolates and deoxynivalenol production. Iran J Plant Pathol. 2010; 46(1): 11-3.

22. Gandomi H, Misaghi A, Basti AA, Bokaei S, Khosravi A, Abbasifar A, et al. Effect of Zataria multiflora Boiss . essential oil on growth and aflatoxin formation by Aspergillus flavus in culture media and cheese. Food Chem Toxicol. 2009; 47(10): 2397-400.

23. Li B, Su T, Xie G, Wang YL. Effect of chitosan solution on the inhibition of Pseudomonas fluorescens causing bacterial head rot of broccoli. Plant Pathol J. 2010; 26(2): 189-93.

24. Avrova AO, Hyman LJ, Toth RL, Toth IK. Application of amplified fragment length polymorphism fingerprinting for taxonomy and identification of the soft rot bacteria Erwinia carotovora and Erwinia chrysanthemi. Appl Environ Microbiol. 2002; 68(4): 1499-508.

25. Duarte V, De Boer S, Ward L, Oliveira A. Characterization of atypical Erwinia carotovora strains causing blackleg of potato in Brazil. J Appl Microbiol. 2004; 96(3): 535-45.

26. Zhang H, Kong B, Xiong YL, Sun X. Antimicrobial activities of spice extracts against pathogenic and spoilage bacteria in modified atmosphere packaged fresh pork and vacuum packaged ham slices stored at $4 C$. Meat science. 2009; 81(4): 686-92.

27. NCCLS, Institute CLS. Methods for dilution antimicrobial susceptibility tests for bacteria that grow aerobically. Appproved standard M7-A7. 2006.

28. Kammoun M, Haddar M, Kallel TK, Dammak M, Sayari A. Biological properties and biodegradation studies of chitosan biofilms plasticized with PEG and glycerol. Int J Biol Macromol. 2013; 62:433-8. 
29. Smith-Palmer A, Stewart J, Fyfe L. The potential application of plant essential oils as natural food preservatives in soft cheese. Food Microbiol. 2001; 18(4): 463-70.

30. Goni P, López P, Sánchez C, Gómez-Lus R, Becerril $\mathrm{R}$, Nerín C. Antimicrobial activity in the vapour phase of a combination of cinnamon and clove essential oils. Food Chemistry. 2009; 116(4): 982-9.

31. Abdolmaleki M, Bahraminejad S, Abassi S, Mahmodi S. Inhibitory effect of some plant extracts onmycelia growth of Rhizoctonia solani and Phytophthora drechsleri, sugar beet rootrot agent. J Sugar Beet. 2010; 25: 193-205.

32. Amini M, Safaie N, Salmani M, Shams-Bakhsh M. Antifungal activity of three medicinal plant essential oils against some phytopathogenic fungi. trakia $\mathrm{j}$ sci. 2012; 10(1): 1-8.

33. Kong B, Wang J, Xiong YL. Antimicrobial activity of several herb and spice extracts in culture medium and in vacuum-packaged pork. J Food Prot. 2007; 70(3): 641-7.

34. Matan N, Rimkeeree H, Mawson A, Chompreeda P, Haruthaithanasan V, Parker M. Antimicrobial activity of cinnamon and clove oils under modified atmosphere conditions. Int J Food Microbiol. 2006;107(2):180-5.

35. Mohamed NH, El-Hadidy AM. Studies of biologically active constituents of Verbascum eremobium Murb. and its inducing resistance against some diseases of cucumber. Egypt J Phytopathol. 2008; 36: 133-50.

36. dos Santos NST, Athayde Aguiar AJA, de Oliveira CEV, Veríssimo de Sales C, de Melo e Silva S, Sousa da Silva R, et al. Efficacy of the application of a coating composed of chitosan and Origanum vulgare L. essential oil to control Rhizopus stolonifer and Aspergillus niger in grapes (Vitis labrusca L.). Food Microbiol. 2012; 32(2): 345-53.

37. Jay JM, Loessner MJ, Golden DA. Modern food microbiology: Springer; 2005.

38. Simić A, Soković M, Ristić M, Grujić-Jovanović S, Vukojević J, Marin P. The chemical composition of some Lauraceae essential oils and their antifungal activities. Phytother Res. 2004; 18(9): 713-7.

39. Unlu M, Ergene E, Unlu GV, Zeytinoglu HS, Vural $\mathrm{N}$. Composition, antimicrobial activity and in vitro cytotoxicity of essential oil from Cinnamomum zeylanicum Blume. Food Chem Toxicol. 2010 Nov;48(11):3274-80. doi: 10.1016/j.fct.2010.09.001. 40. Can Baser K. Biological and pharmacological activities of carvacrol and carvacrol bearing essential oils. Curr Pharm Des. 2008; 14(29): 3106-19.

41. Saei-Dehkordi SS, Tajik H, Moradi M, KhalighiSigaroodi F. Chemical composition of essential oils in Zataria multiflora Boiss . from different parts of Iran and their radical scavenging and antimicrobial activity. Food Chem Toxicol. 2010; 48(6): 1562-7. doi: 10.1016/j.fct.2010.03.025.
42. Ponce AG, Roura SI, del Valle CE, Moreira MR. Antimicrobial and antioxidant activities of edible coatings enriched with natural plant extracts: In vitro and in vivo studies. Postharvest Biol Technol. 2008; 49(2): 294-300. doi:10.1016/j.postharvbio.2008.02.013

43. Ravishankar S, Zhu L, Reyna-Granados J, Law B, Joens L, Friedman M. Carvacrol and cinnamaldehyde inactivate antibiotic-resistant Salmonella enterica in buffer and on celery and oysters. J Food Prot. 2010; 73(2): 234-40.

44. Azarfar A, Alipour D, Malecky M, Talebzadeh R, Saharkhiz M. Effect of essential oils of Zataria multiflora on in vitro rumen fermentation, protozoal population, growth and enzyme activity of anaerobic fungus isolated from Mehraban sheep. Animal Feed Science and Technology. DOI: 10.1016/j.anifeedsci.2011.11.011.

45. Ultee A, Bennik M, Moezelaar R. The phenolic hydroxyl group of carvacrol is essential for action against the food-borne pathogen Bacillus cereus. Appl Environ Microbiol. 2002; 68(4): 1561-8.

46. Jirovetz L, Bail S, Buchbauer G, Denkova Z, Slavchev A, Stoyanova A, et al. Antimicrobial testings, gas chromatographic analysis and olfactory evaluation of an essential oil of hop cones (Humulus lupulus L.) from Bavaria and some of its main compounds. Sci Pharm. 2006;74(4):189.

47. Atti-Santos A, Pansera M, Paroul N, Atti-Serafini L, Moyna P. Seasonal variation of essential oil yield and composition of Thymus vulgaris L.(Lamiaceae) from South Brazil. J Essent Oil Res. 2004; 16(4): 294-5.

48. Angioni A, Barra A, Coroneo V, Dessi S, Cabras P. Chemical composition, seasonal variability, and antifungal activity of Lavandula stoechas L. ssp. stoechas essential oils from stem/leaves and flowers. J Agric Food Chem. 2006; 54(12): 4364-70.

49. Al-Ani RA, Adhab MA, Nawar HH. Antibacterial activity of clove, cinnamon, and datura extracts against Erwinia carotovora subsp. atroseptica causative agent of black stem and soft rot on potato. J Med Plants Res. 2012; 6: 1891-5.

50. El-Zemity SR, Radwan MA, El-Monam Mohamed SA, Sherby SM. Antibacterial screening of some essential oils, monoterpenoids and novel $N$-methyl carbamates based on monoterpenoids against Agrobacterium tumefaciens and Erwinia carotovora. Arch Phytopathol Plant Protect. 2008; 41(6): 451-61.

51. Maffei M, Sacco T. Chemical and morphometrical comparison between two peppermint notomorphs. Planta Med. 2007; 53(02): 214-6. 